TAO, Vol. 13, No. 1, 53-64, March 2002

\title{
Mapping of the Simultaneous Movement of the Equatorial Ionization Anomaly (EIA) and Ionospheric Plasma Bubbles Through All-sky Imaging of OI $630 \mathrm{~nm}$ Emission
}

\author{
G. K. Mukherjee ${ }^{1, *}$ \\ (Manuscript received 15 May 2001, in final form 9 January 2002)
}

\begin{abstract}
An all-sky imager with $180^{\circ}$ field of view has been operating at Kolhapur $\left(16.8^{\circ} \mathrm{N}, \mathbf{7 4 . 2}^{\circ} \mathrm{E}\right.$; $\operatorname{dip}$ lat $\left.10.6^{\circ} \mathrm{N}\right)$ in India to study the ionosphere-thermosphere dynamics through the imaging of OI $630.0 \mathrm{~nm}$ oxygen emission line. It is observed that large number of events are characterized by the development of strong Equatorial Ionization Anomaly (EIA). Two examples of equatorward movement of the Appleton Anomaly crests (reverse ionization anomaly) with speed of $36-40 \mathrm{~m} / \mathrm{s}$ on the night of January 26,1998 and January 18, 1999 during the observation of ionospheric bubbles have been reported showing the observed correlation between EIA and bubbles. Our results agree well with those of Sridharan et al. (1993) regarding the movement of the reverse fountain from Indian low latitude region. Generally, the background emission rates were low when no bubbles were observed.
\end{abstract}

(Key words: Appleton anomaly, Ionospheric plasma bubbles, OI $630 \mathrm{~nm}$ emission)

\section{INTRODUCTION}

Ionospheric plasma irregularities associated with nighttime equatorial spread-F (ESF) phenomena have been extensively studied at different longitude zones in a wide range of altitudes, starting from lower F-region to regions beyond $1000 \mathrm{~km}$ in the last two-three decades by using both radio and in-situ techniques (incoherent back scatter radar, rockets, satellites and UHF/ VHF scintillation, ionosondes, topside sounder) as well as optical techniques (conventional tilting and scanning photometers and wide angle imaging system) (Weber et al. 1978; Fagundes et al. 1999; Kil and Heelis 1998; Mendillo et al. 1997; Singh et al. 1997; Sahai et al. 1994, 1996; Taylor et al. 1997). The scale size of the irregularities varies between a few centimeters to several hundred kilometers in geomagnetic field perpendicular direction (Abdu 1993).

Several research workers have used wide-angle optical imaging technique of F-region nightglow emissions to study large-scale equatorial plasma irregularities. These are regions where the plasma densities decrease abruptly few orders of magnitude compared to the ambi-

\footnotetext{
${ }^{1}$ Indian Institute of Geomagnetism, Colaba, Mumbai - 400005

${ }^{\star}$ Corresponding author address: Dr. G. K. Mukherjee, Indian Institute of Geomagnetism, Colaba, Mumbai - 400 005; E-mail: gkm@iig.iigm.res.in
} 
ent plasma densities. The importance of studies of ionospheric plasma irregularities grew because of their strong influence on ionospheric and trans -ionospheric communications. These low intensity regions which are optical signature of bubbles or depletions which have been mapped in the all-sky images of OI $630.0 \mathrm{~nm}, 557.7 \mathrm{~nm}$ and $777.4 \mathrm{~nm}$ emissions at a low latitude station, Kolhapur (Mukherjee et al. 1999).

The plasma in the magnetic field tubes tend to diffuse along F-region magnetic field lines while moving upwards because of greater conductivity parallel to the magnetic field lines than perpendicular to them. This will make the depleted plasma regions field aligned. While the bubbles drift eastward with the background plasma, the depleted plasma regions appear to tilt in the westward direction. These depleted regions are not homogeneous and within their boundaries exist the smaller scale size irregularities (a few meters to kilometers in size) which gives rise to strong VHF / UHF scintillations in satellite beacon signals.

The use of all-sky optical imaging system has been especially important in studying the spatial extent of the bubble and their motion relative to both the ground and to the surrounding ambient ionosphere (Mendillo et al. 1997). A CCD based all-sky imaging system (180 of view) developed in collaboration with Boston University, U.S., was operated from Kolhapur on clear moonless nights to obtain the signature and dynamics of plasma bubbles by studying the images at OI $630.0 \mathrm{~nm}, 557.7 \mathrm{~nm}$ and $777.4 \mathrm{~nm}$. The data for the generation and evolution of these large-scale irregularities is limited at the Indian longitude sector (Mukherjee et al. 1998). The location of the observing station is important as a single image frame at a given instant provides information regarding the dynamics of these irregularities over a large low latitude region starting from geomagnetic equator to equatorial ionospheric anomaly region. These observations also permitted us to acquire a large comprehensive database for studying the growth and evolution of equatorial ionospheric plasma bubbles.

It is generally believed that the bubbles or depletions are produced in the bottom side of the F-region after sunset triggered by gravity waves under certain conditions when the bottom side of the F-region becomes unstable for the growth of a fluid type gradient instability mechanism such as Rayleigh-Taylor Instability (Dungey 1956). The linear growth rate is given by

$$
\gamma=\nabla \mathrm{n} / \mathrm{n}\left(\mathrm{g} / \mathrm{v}_{\mathrm{in}}+\mathrm{E} / \mathrm{B}\right) .
$$

Where $\nabla \mathrm{n}$ is the gradient in electron density $\mathrm{n}, \mathrm{v}_{\mathrm{in}}$ is the ion-neutral collision frequency, $\mathrm{E}$ and $\mathrm{B}$ are the electric and magnetic fields and $\mathrm{g}$ is the gravitational acceleration.

Basically, the thermospheric zonal wind that blows across the sunset terminator is responsible for the F-layer dynamo electric field (Rishbeth 1971). The longitudinal gradient in the Elayer Pederson conductivity and the gradient in the Hall conductivity result in the generation of an eastward (pre reversal) electric field which contributes to the vertical upliftment of the layer and it adds to the instability growth rate factor $(\gamma)$. The electric field contributes to $(\gamma)$ indirectly through its effect on $g / v_{\text {in }}$ and $\nabla n / n$. Several studies have shown that the height of the nighttime F-layer is the single most important parameter controlling the generation of spread-F irregularities (Patel 1974; Woodman 1970). Recently Whalen (2000) showed a clear relationship and understanding among a bubble, range type spread-F and the development of 
ionization anomaly. There was no coordinated scintillation observations available during these measurements. However, the intersection of the bubble with the crest maximum is known to be the focus of maximum scintillation from many other experiments. The enhanced equatorial Appleton anomaly comprises of two regions of increased electron density maximum at $\pm 15^{\circ}$ dip latitude. It was observed by Mendillo et al. (1992) that if the anomaly is well developed and symmetrical about the equator then it helps in the generation of Spread-F irregularities. The generation of ionospheric plasma bubbles and the anomaly enhancement generally occur continuously following sunset. Rastogi (1989) has pointed out, that Spread-F at equatorial stations is preceded by marked rise of h'F during post sunset hours. Sahai et al. (1996) also reported that in addition to uplifting of the post sunset F-layer at equatorial station, Fortaleza $\left(3.9^{\circ} \mathrm{S}, 38.4^{\circ} \mathrm{W}\right)$ during the period of observation of plasma bubbles, there was a considerable increase in afternoon foF2 (critical frequency of the F- layer) values at off equatorial station, Cachoeira Paulista $\left(22.7^{\circ} \mathrm{S}, 45.0^{\circ} \mathrm{W}\right)$ compared to the values at the equatorial station at Brazil sector.

In this report, we study the simultaneous observation of the movement of reverse ionization anomaly and the development of ionospheric plasma bubbles from a low latitude station, Kolhapur in India.

\section{INSTRUMENTATION}

The design features of a CCD based imaging system have been explained by number of research workers (Baumgardner and Karandanis (1984); Mendillo et al. (1989)) and more recently by Mukherjee et al. (1998). The fish-eye lens ( $16 \mathrm{~mm}, \mathrm{f} / 2.8$ ) at the top of the camera (Fig.1) allows light in $2 \pi$ steradians from the sky to enter into the system. The $40 \mathrm{~mm}$ diameter field lens and the $300 \mathrm{~mm} \mathrm{f/2.5} \mathrm{Aero} \mathrm{Ektar} \mathrm{lens} \mathrm{act} \mathrm{as} \mathrm{collimators.} \mathrm{The} \mathrm{fish} \mathrm{eye} \mathrm{lens}$

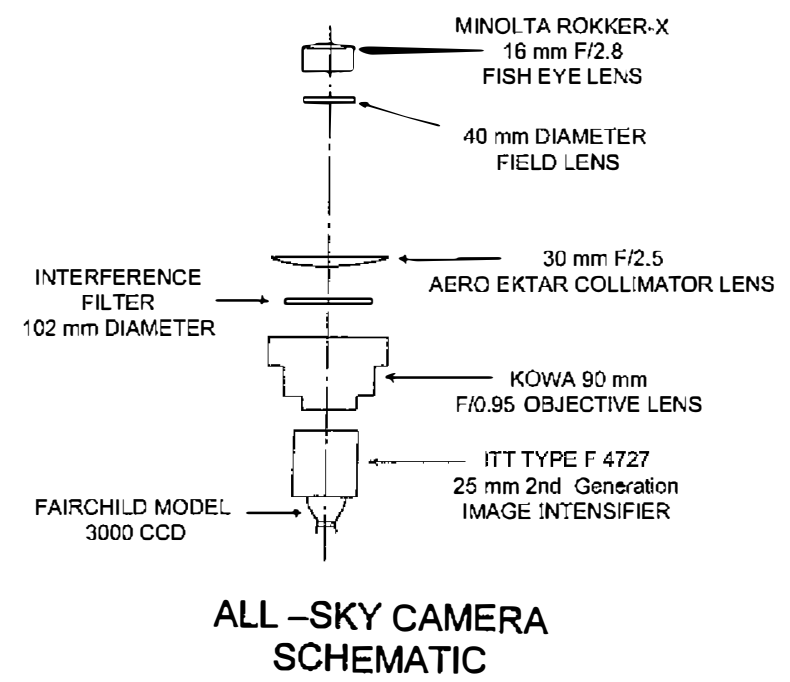

Fig. I. Schematic diagram of the all-sky camera.. 
produces a circular image of the sky $23 \mathrm{~mm}$ in diameter, which is directed into the collimator. Finally the light after passing through the filter is reimaged at $\mathrm{f} / 1$. onto the photo cathode of the intensified CCD of Fairchild Model 3000 and intensifier type 4727 of ITT. The detector is housed in a chamber thermoelectrically cooled to $60^{\circ} \mathrm{C}$ below ambient temperature to reduce the dark signal. Very weak nightglow signals of few Rayleigh in intensity can be monitored with the system with large integration time. With indexed color images, the system maintains a color table, of up to 256 colors with value 0 (blue) to highest value 255 (magenta) called the data number. The product of the data number and the constant (Rayleigh / data number) of the calibrated source would give the absolute intensity in Rayleigh. There are six filter positions, which can be used to study various emission lines originating at different ionospheric-thermospheric heights. Since our main concern is to study F-region dynamics at night, we concentrate mainly on spatial and temporal characteristics of OI $630 \mathrm{~nm}$ emission. The spectral line at 630 $\mathrm{nm}$ is indicative of dissociative recombination involving $\mathrm{O}_{2}$ molecules and electrons near 300 km altitude (Mukherjee and Dyson 1992).

\subsection{Geometry of Observations}

Figure 2 shows the location of the observing station Kolhapur with respect to geographic co-ordinates. The two circles indicate the coverage of the camera system for zenith distances $75^{\circ}$ and $90^{\circ}$ for an emission height of $300 \mathrm{~km}$. Figure 3 shows the $75^{\circ}$ zenith angle distance of $300 \mathrm{~km}$ height which encompasses approximately $8^{\circ}$ of latitude / longitude from the zenith which is equivalent to a horizontal diameter of $\sim 1800 \mathrm{~km}$ through the zenith at $300 \mathrm{~km}$. Between zenith angles $75^{\circ}-90^{\circ}$, an additional $8^{\circ}$ latitude / longitude are encompassed. Due to compression effects these regions are not very accurate for image analysis. It is important to note, however, that the geomagnetic equator falls within $75^{\circ}-90^{\circ}$ zenith angles and appears near the southern edge of the field of view. Figure 4 shows the image overlay pattern as seen from Kolhapur. The north-south extent of the bubbles at 300 kilometer altitude can be used to find bubble altitude (or apex height) above the magnetic equator through the mapping of mag-

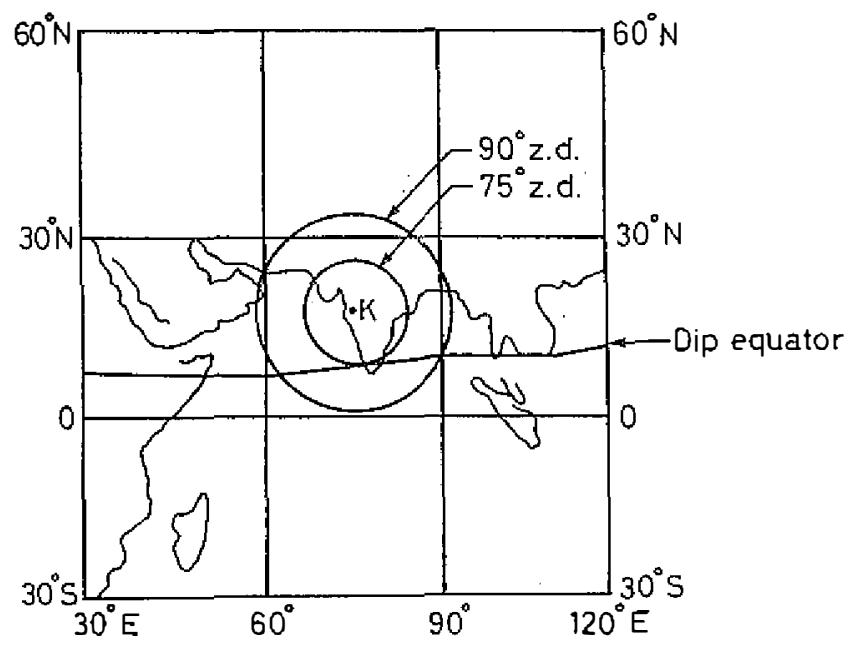

Fig. 2. Field of view at $75^{\circ}$ and $90^{\circ}$ zenith angles at $300 \mathrm{~km}$ for the all-sky camera at Kolhapur. 


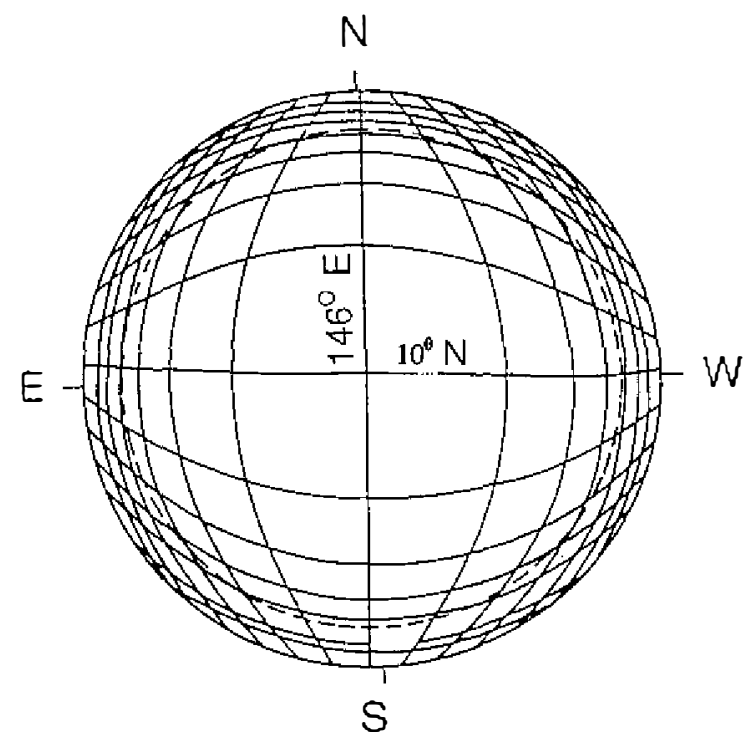

Fig. 3. Dip Latitudes and magnetic longitudes of geomagnetic field lines at $2^{\circ}$ interval observed at $300 \mathrm{~km}$ altitude at Kolhapur.

netic field line. A depleted region reaching the extreme northern edge of the image will correspond to an altitude greater than $1500 \mathrm{~km}$ above the equator.

\section{RESULTS}

\subsection{Movement of Equatorial Ionization Anomaly (EIA)}

\subsubsection{Observation on January 26, 1998}

The average decimetric solar flux indices $\left(\mathrm{F} 10.7 \mathrm{~cm}\right.$ ) for the day was (units of $10^{-22} \mathrm{w} \mathrm{m}^{-2}$ ) 97 and the average of the $\mathrm{Kp}$ indices during the period of observation was 1 . It was a typically magnetically quiet night with low solar activity. All-sky images were taken with $630 \mathrm{~nm}$ filter at every minute. The time is expressed in IST (Indian Standard Time), which is ahead of UT by five and half hours. The north-south aligned depletions were first observed around $2100 \mathrm{hrs}$ and the Fig. 5 shows the movement of the Appleton anomaly (reverse ionization anomaly) during the night. Generally, the equatorial region at the extreme south of the image shows very low $630 \mathrm{~nm}$ intensity as the F-layer is situated at higher altitude in the evening hours, recombination is low due to smaller values of ion-neutral frequency at F-region altitudes. The sequence of images in Fig. 5 shows two interesting phenomena. The bubble (low intensity) drifted eastward along with its movement towards the north while rising at higher altitudes at the equator while the equator ward movement of the anomaly (high intensity region) continues as inferred from the subsequent images. The inward motion (northward direction) of the top of the bubble is in opposite direction to the inward drift (ExB) of the bulk plasma towards the equator. Using the Fig. 3 and the sequence of images, the drift speeds were computed which vary between $36-40 \mathrm{~m} / \mathrm{s}$. The bubble at $2150 \mathrm{hrs}$ reaches $1500 \mathrm{~km}$ apex height (Fig. 4) and the average bubble rise velocity at the equator turns out to be $110 \mathrm{~m} / \mathrm{s}$. Figures 6 (a) and (b) show the OI $630 \mathrm{~nm}$ image and its three dimensional projection in intensity depicting the north- 


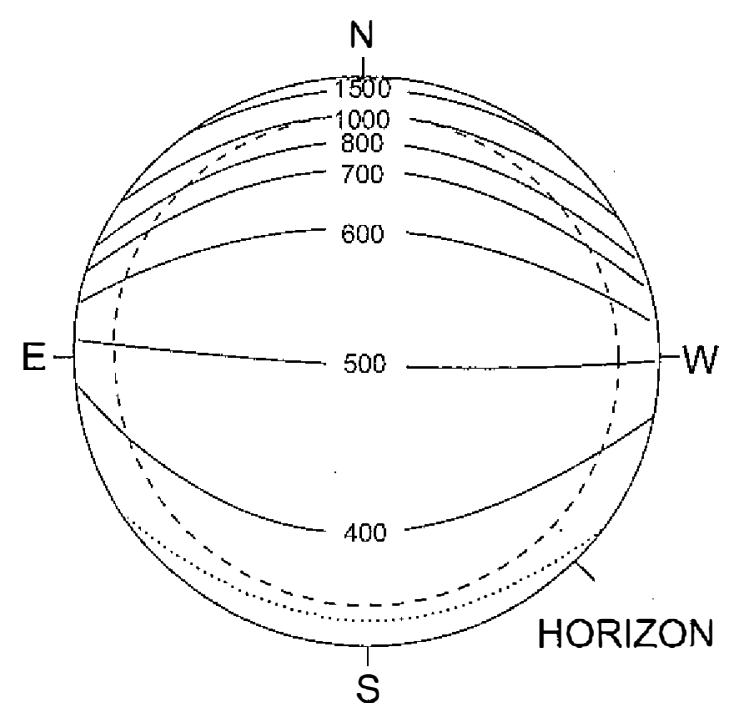

Fig. 4. Projected altitude over the equator for OI $630.0 \mathrm{~nm}$ emission at $300 \mathrm{~km}$ for Kolhapur situated at the center. Dotted line represents the magnetic equator, dashed line represents a $75^{\circ}$ zenith distance.

south aligned depletion region tilted towards the west [black color in (a)] and the depth of depletion (low electron density area) in (b) for the night of January 26, 1998. Note also very low OI $630 \mathrm{~nm}$ intensity observed in the southern part and very high intensity in the northern part of the sky in both the images showing strong meridional gradient in intensity in (b). The bright intensity region in the northern part of the image is due to movement of the ionization anomaly to the southern direction.

\subsubsection{Observation on January 18, 1999}

The average decimetric solar flux indices $(\mathrm{F} 10.7 \mathrm{~cm})$ for the day were 165 units and the average of the $\mathrm{Kp}$ indices during the period of observation was 2 . It was a typically magnetically quiet night with moderate solar activity. All-sky images were taken with $630 \mathrm{~nm}$ filter with integration time of about one minute. Figure 7 shows the $\mathrm{OI} 630 \mathrm{~nm}$ images taken during the night of January 18, 1999 with six frames; it depicts another example of the movement of the Appleton Anomaly during the night from north to south with drift speed of $36-40 \mathrm{~m} / \mathrm{s}$. The high intensity region is shown by dark color. At $22: 30 \mathrm{hrs}$ the $\mathrm{Ol} 630 \mathrm{~nm}$ intensities are stronger at the northem edge and very weak at the southem part of the sky. The north-south aligned plasma depleted region (ionospheric plasma bubble) is shown at the center, the structure moves towards the east gradually shown in the subsequent images. At 23:04 hrs the bubble reaches an apex altitude of about $1200 \mathrm{~km}$, simultaneously another bubble (depleted in OI $630 \mathrm{~nm}$ intensity) appears at the western part of the sky at 22:42 hrs. The upper portion of the bubble breaks into two shown clearly on the images observed at 2304, 2314 and $2323 \mathrm{hrs}$ IST. Apart from the north-south and eastward movement of the bubble, the background plasma or the reverse ionization anomaly shown by an arrow also drifts towards the south(equator). This confirmed 


\section{KOLHAPUR \\ JANUARY 26, 1998 \\ OI $630 \mathrm{~nm}$}
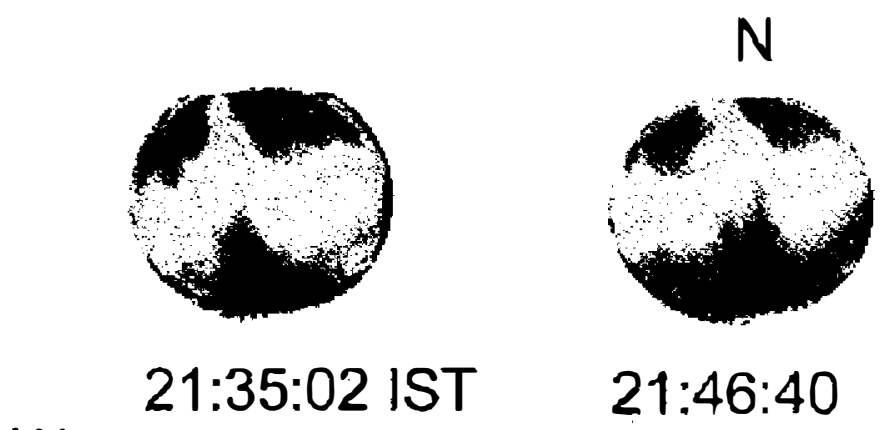

w
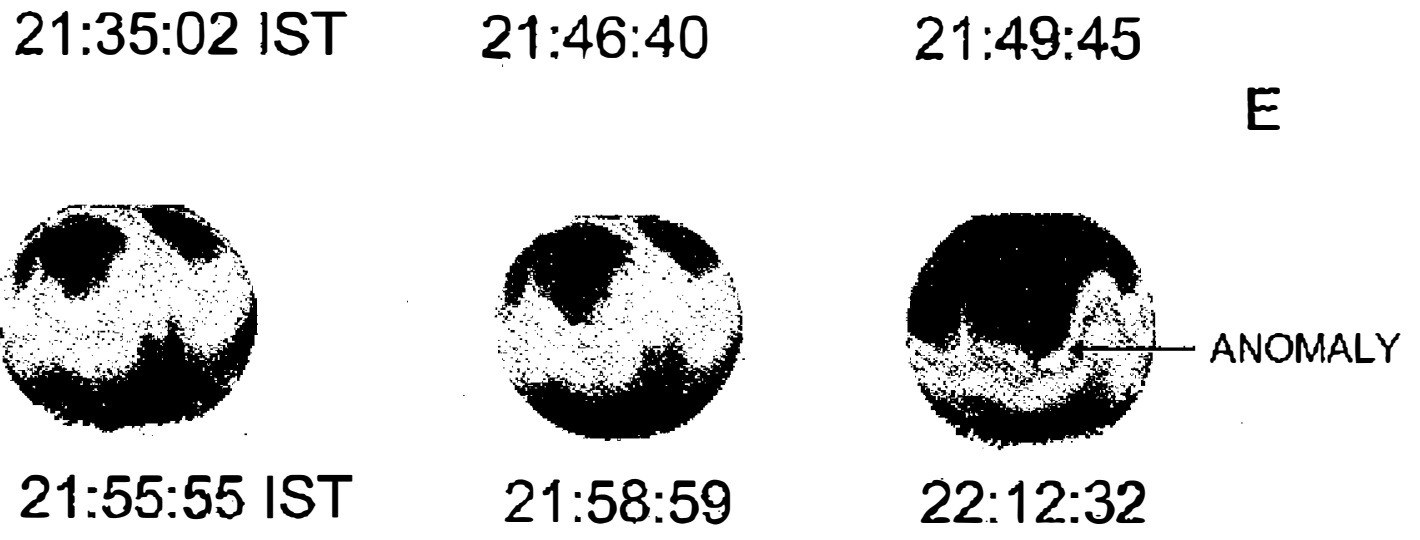

22:12:32

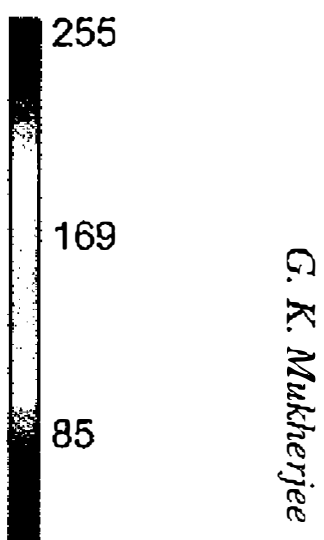

$\mathrm{S}$

Fig. 5. Movement of the reverse ionization anomaly with drift speeds of $36-40 \mathrm{~m} / \mathrm{s}$ on the night of January 26 , 1998. Note also the eastward movement of the bubble along with its vertical rise in altitude extending increasingly northward. 
KOLHAPUR

OI $630 \mathrm{~nm}$ IMAGE

January 26, 1998

$21: 35$ hrs IST

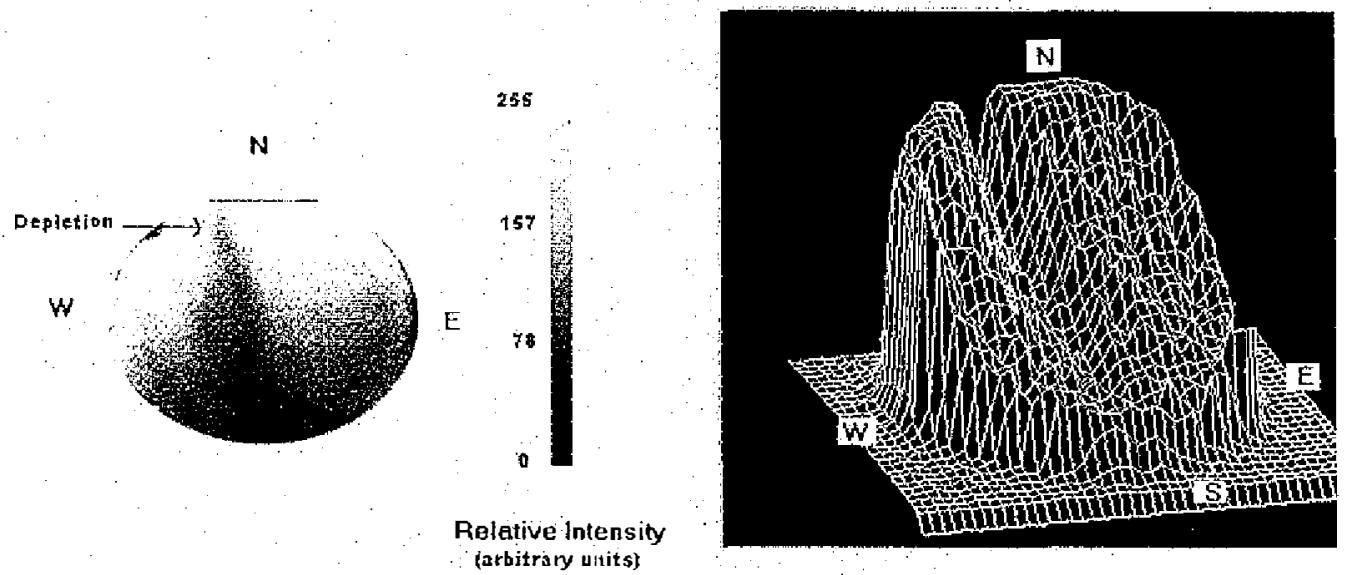

Fig. 6. An airglow image( OI $630 \mathrm{~nm}$ ) showing the north-south aligned ionospheric plasma depletions( bubbles) tilted towards west ( black color) in (a) and its three dimensional projection in intensity showing the depth of depletion in (b) on January 26, 1998 at 21:35 hrs IST.

that during the period of observation of bubbles at the low latitudes, the anomaly was well developed and fairly strong.

\section{DISCUSSION AND CONCLUSION}

The present study has brought out an integrated view of the phenomena like the development of ionospheric plasma bubbles embedded in ambient plasma and the anomaly enhancement in the low latitude Indian region. The drift speed of reverse EIA from north to south direction at night has been inferred from successive OI $630.0 \mathrm{~nm}$ images (Figs. 5 and 7) to be $36-40 \mathrm{~m} / \mathrm{s}$ when there was strong development of EIA shown by an arrow in the diagram.

The daytime F-region is controlled by a delicate balance between production of ionization through photo ionization and loss due to chemical and plasma transport processes. In the vicinity of the dip equator, vertical diffusion of plasma is not possible without the imposition of an applied electric field because of unique configuration of the geomagnetic field. Such an electric field originates due to the global E-region dynamo driven by tidal winds. The E-region east-west electric field can be mapped to the F-region through the highly conducting geomagnetic field lines and controls the plasma movement in the vertical direction through $\mathrm{E} x \mathrm{~B}$ drift (Heelis et al. 1974). Besides, as the gyro-frequency is much larger than the ion-neutral frequency at F-region heights, the plasma once lifted upwards can diffuse along the geomagnetic field lines under the influence of pressure and gravitational gradient forces. Martyn (1947) 


\section{JANUARY 18, 1999 KOLHAPUR Ol $630 \mathrm{~nm}$}

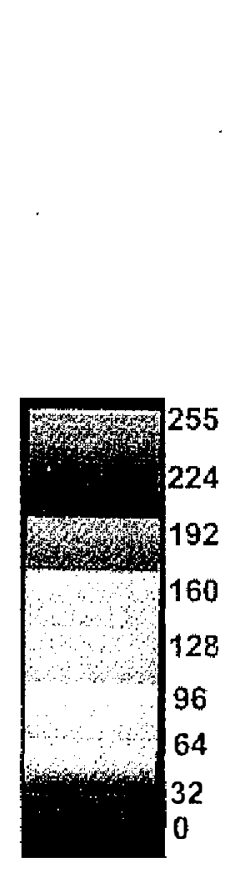

Relative Intensity (arb. units)
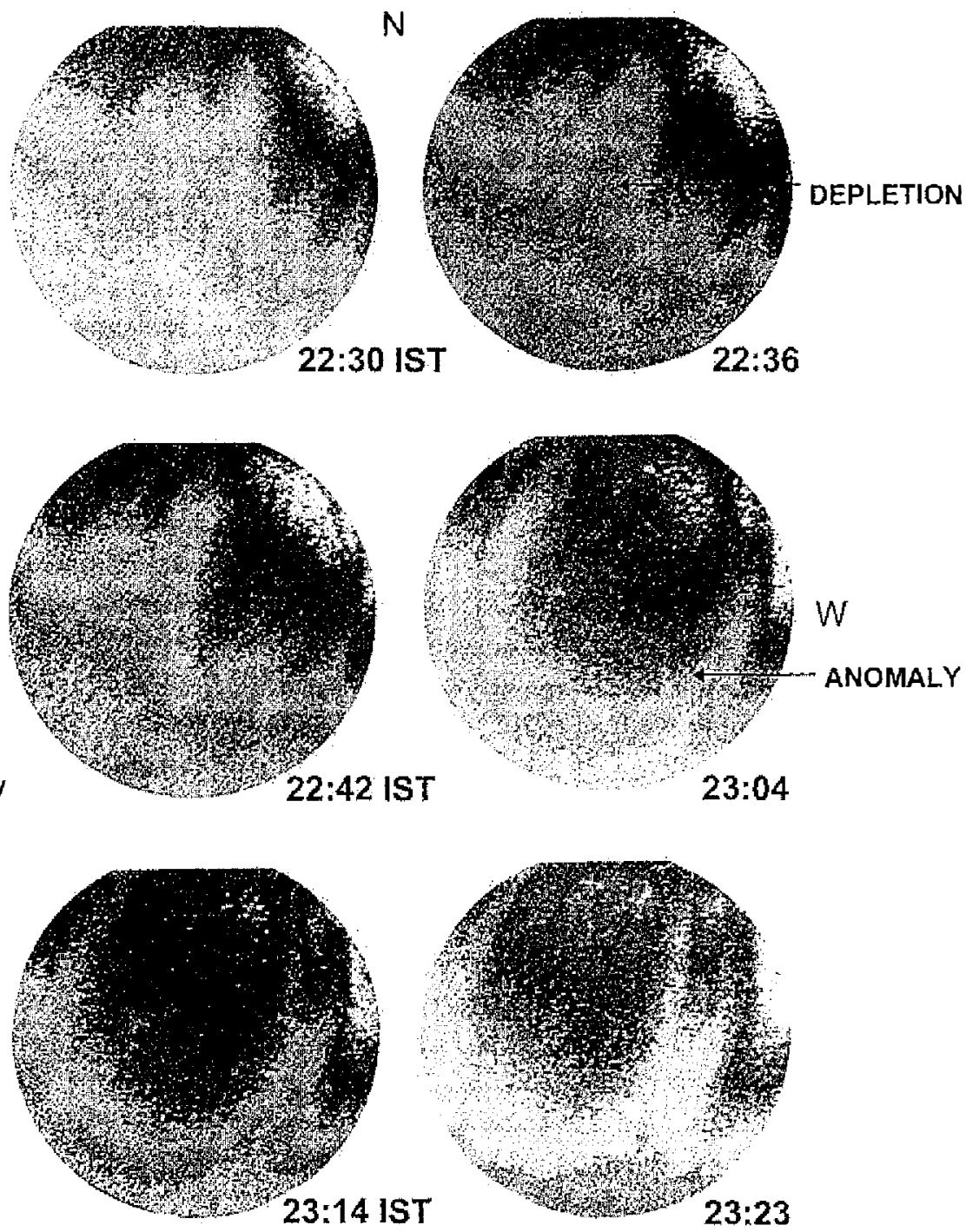

S

Fig. 7. Movement of the reverse ionization anomaly with drift speeds of 36-40 $\mathrm{m} / \mathrm{s}$ on the night of January 18,1999 . Note also the eastward movement of the bubble along with its vertical rise in altitude extending increasingly northward. 
proposed the anomaly was due to the combined action of vertical drifts of ionization near dip equator and its subsequent diffusion to higher latitudes, which is well known as fountain effect. Usually during the nighttime, the zonal electric field changes direction and becomes westward. As a result the plasma moves equatorward as seen at an off equator latitudes, which is known, as reverse ionization anomaly. Hanson and Moffett (1966) also modeled a reverse fountain, which produced equatorial ridge of electron density. Since the 24-hour average of the vertical drift velocity must be equal to zero for the ionosphere, the upward drift by daytime must be balanced by downward drift at night.

Using the electron (e-h profile) density $\left(\mathrm{N}_{\mathrm{A}}\right.$ and $\left.\mathrm{N}_{\mathrm{w}}\right)$ data of Ahmedabad (dip latitude 18. $6^{\circ} \mathrm{N}$ ) and Waltair (dip latitude $10.6^{\circ} \mathrm{N}$ ) in the Indian longitude zone, it was observed by Raghavarao et al. (1988) that there was an enhancement in the electron density ratio $\left(\mathrm{N}_{\mathrm{A}} / \mathrm{N}_{\mathrm{w}}\right)$ by a factor of 8 to 30 between the two stations around local evening hours compared to their day time values $\left(\mathrm{N}_{\mathrm{A}} / \mathrm{N}_{\mathrm{w}}\right)$ on spread-F days. This was shown as an evidence of intensification of northem crest of the equatorial ionization anomaly situated near Ahmedabad during spread$F$ nights. No such enhancement in electron density ratio $\left(\mathrm{N}_{A} / \mathrm{N}_{\mathrm{w}}\right)$ was seen on nights without spread-F. Using the ALTAIR incoherent scatter radar and all-sky imaging technique at Kwajalein Atoll (Marshal Islands), Mendillo et al. (1992) showed ESF onset occurred when the airglow patterns associated with the equatorial anomaly was essentially symmetrical about the geomagnetic equator which is likely the case when the meridional winds are weak. But the visual representation of the anomaly or fountain movement has not been brought out earlier so clearly as the present imaging observation shows. As the all-sky camera covers a distance of $1800 \mathrm{~km}$ in north-south and east-west directions at $150^{\circ}$ field of view at $300 \mathrm{~km}$ altitude, the spatial and temporal movement of the anomaly is well documented. The determination of the drift velocity of the fountain was done earlier from Indian longitude sector by a simple scanning photometer unit by Kulkarni (1975) and obtained an estimate of the velocity of reverse fountain as $42 \mathrm{~m} / \mathrm{s}$. They also found that in the years of low sunspot activity the intensity of the EIA is weak and its southward velocity is less on magnetically disturbed nights. Also, using an imaging interferometer at Mt. Abu ( $\left.24^{\circ} 36^{\prime} \mathrm{N}, 72^{\circ} 43^{\prime} \mathrm{E}\right)$, Sridharan et al. (1993) estimated the drift speed of the movement of the reverse fountain as $40 \mathrm{~m} / \mathrm{s}$. However, the estimate was made from the movement of brightness structure within a narrow field of view $\left(<6^{\circ}\right)$ as seen by the interferometer. Our results $(36-40 \mathrm{~m} / \mathrm{s})$ reconfirm the earlier results from this longitude zone. It is well known that EIA displays a highly localized effect and it is generally well developed at a particular latitude and longitude sector and the effect might diminish at near by region. But the spatial extent (about $8^{\circ}$ ) in both longitude and latitude of the Appleton Anomaly has been inferred from the present study.

Fejer et al. (1999) showed when upward drift velocities are larger than $5-10 \mathrm{~m} / \mathrm{s}$ near solar minimum, narrow unstable layer of weak irregularities are generated in all seasons at F-region heights at Jicamarca. If there is a rapid downward motion of the layer in the evening hours, the weakening of the unstable layer takes place due to unusually large downward drift velocities driven by westward electric field. Generally, a large downward drift followed by a positive drift which remains steady for more than an hour gives rise to spread-F irregularities. The motion of these bottom type irregularities is dominated by E-region dynamo electric fields. It is now well accepted that a perturbation electric field in the base of the F region is required to 
trigger the growth of plumes in the equatorial Spread-F. It is also believed that these perturbation electric fields can be produced by gravity waves. Prakash (1999) also showed that observed spacing of the plumes is much smaller than the horizontal wavelength of the gravity waves. This gives an idea that these perturbation electric fields are generated by the gravity wave wind in the $\mathrm{E}$ region connected to the base of the F-region via conducting geomagnetic field lines.

Acknowledgements The all-sky camera has been developed with the collaboration of Prof, M. Mendillo and his group at Boston University, Boston, and U.S.A. The author is grateful to Prof. M. Mendillo for his continued interest in the project. Department of Science and Technology (DST), Government of India, New Delhi funds the research in upper atmospheric science in IIG. The nightglow observations at Kolhapur were carried out under scientific collaboration between IIG, Mumbai and Shivaji University, Kolhapur.

\section{REFERENCES}

Abdu, M. A., 1993: Equatorial spread-F and ionosphere-thermosphere system: A review, Trends. Geophys. Res., 2, 193-209.

Baumgardner, J., and S. Karandanis, 1984: CCD system using video graphics controller. Electronic Imaging, 3, 28-31.

Dungey, J. W., 1956: Convective diffusion in the equatorial F region . J. Atmos. Terr. Phys., 9, 304-310.

Fagundes, P. R., Y. Sahai, I. S. Batista, M. A. Abdu, J. A. Bittencourt, and H. Takahashi, 1999: Observations of day-to-day variability in precursor signatures in equatorial Fregion plasma depletions. Ann. Geophys., 17, 1053-1063.

Fejer, B. G., L. Scherliess, and E. R. de Paula, 1999: Effects of the vertical drift velocity on the generation and evolution of equatorial spread-F. J. Geophys. Res., 104, 1985919869.

Hanson, W. B., and R. J. Moffett, 1966: Ionization transport effects in the equatorial F region. J. Geophys. Res. 71, 5559 - 5572.

Heelis, R. A., P.C. Kandall, R. J. Moffett, D. W. Windle, and H. Rishbeth, 1974: Electric Coupling of the $\mathrm{E}$ and $\mathrm{F}$ regions and its effect on $\mathrm{F}$-region drifts and winds. Planet. Space Sci., 22, 743-756.

Kil, H., and R. A. Heelis, 1998: Global distribution of density irregularities in the equatorial ionosphere. J. Geophys. Res.,103, 407-417.

Kulkarni, P. V.,1975: $6300 \AA$ night airglow and the geomagnetic control of the equatorial anomaly. Proc. Ind. Acad Sci., 82, 46-52.

Martyn, D. F., 1947: Atmospheric tides in the ionosphere. Proc R. Soc., A189, 241-260.

Martyn, D. F.,1959: The normal F-region of the ionosphere. Proc. IRE, 47, 147-155.

Mendillo, M., Jeffrey Baumgardner, Marelene Colerico, and Daniel Nottingham, 1997:Imaging science contributions to equatorial aeronomy: initial results from the MISETA program. J. Atmos. Terr. Phys, 59,1587-1599. 
Mendillo, M., J. Baumgardner, X. Q. Pi, P.J. Sultan, and R. Tsunoda,1992: Onset conditions for equatorial spread-F. J. Geophys. Res., 97, 13865-13876.

Mendillo, M., J. Baumgardner, P. J. Sultan, 1989: Optical and radar techniques applied to chemical release in active experiments in the ionosphere/thermosphere system. $A d v$. Space Res., 10, 8-15.

Mukherjee, G. K., and P. L. Dyson, 1992: A filter tilting photometer for nightglow measurement of $630.0 \mathrm{~nm}$ emission line. Ind. J. Radio Space Phys., 21, 212-217.

Mukherjee, G. K., L. Carlo, S. H. Mahajan, and P. T. Patil, 1998: First results of all-sky imaging from India. Earth Planets and Space, 50, 119-127.

Mukherjee, G. K., L. Carlo, S. H. Mahajan, 1999: On the OI 630 nm, 557.7 nm, 777.4 nm nightglow measurements of equatorial plasma depletions during spread-F events, IUGG conference, July 18-30, Birmingham University, Birmingham , U.K.

Patel, V. L., 1978: Interplanetary magnetic field variations and the electromagnetic state of the equatorial ionosphere. J. Geophys. Res., 83, 2137-2144.

Prakash, S., 1999: Production of electric field perturbations by gravity wave winds in the $\mathrm{E}$ region suitable for initiating equatorial spread-F. J. Geophys. Res.,104, 10051-10069.

Rastogi, R. G., 1989: Spread-F and equatorial fountain of plasma irregularities. Ind J. Radio Space Phys., 18, 95-98.

Raghavarao, R., M. Nageswarrao, J. H. Sastri, G. D. Vyas, and Srirama Rao, 1988: Role of equatorial ionization anomaly in the initiation of equatorial spread-F. J. Geophys Res., 93, 5959-5964.

Rishbeth, H., 1971: The F-layer dynamo. Planet. Space Sci, 19, 263-267.

Sahai, Y., J. Aarons, M. Mendillo, J. Baumgardner, J. A. Bittencourt, and H. Takahashi,1994: OI $630 \mathrm{~nm}$ imaging observations of equatorial plasma depletions at $16^{\circ} \mathrm{S}$ Iatitude. $J$. Atmos. Terr. Phys., 56, 1461-1475.

Sahai, Y., J. A. Bittencourt, J. H. A. Sobral, P. R. Fagundes, and H. Takahashi, 1996: Observations of ionospheric plasma depletions using OI $630.0 \mathrm{~nm}$ nightglow imaging. Revista Bras de Geophys, 14(1), 15-28.

Singh, S., F. S. Johnson, and R. A. Power, 1997: Gravity wave seeding of equatorial plasma bubbles. J. Geophys. Res., 102, 7399-7410.

Sridharan, R., R. Sekar, and S. Gururbaran,1993: Two Dimensional high resolution imaging of the equatorial Plasma Fountain. J. Atmos. Terr. Phys., 55, 1661-1665.

Taylor, M. J., J. V. Eccles, J. Labelle, and J. H. A. Sobral , 1997: High resolution OI (630 nm) image measurements of F-region depletion drifts during the Guara campaign. Geophys. Res. Let., 24(13), 1699-1702.

Weber, E. J., J. Bachau, R. H. Eather, and S. B. Mende,1978: North-south aligned equatorial airglow depletions. J. Geophys. Res., 83, 712-716.

Whalen, J. A., 2000: An equatorial bubble; it's evolution in relation to bottom side spread-F and the appleton anomaly. J. Geophys .Res., 105, 5303-5315.

Woodman, R. F., 1970: Vertical drift velocities and east-west electric field at the geomagnetic equator. J. Geophys., Res., 75, 6249-6259. 